\title{
Los afectos como efectos del lenguaje sobre el cuerpo: de las pasiones de Aristóteles a los afectos en la teoría psicoanalítica de Freud y Lacan
}

\author{
Affections as effects of language on the body: from Aristotle's \\ passions to affections in freudian and lacanian psychanalysis
}

FRANCISCO CONDE SOTO*

\begin{abstract}
Resumen: El objetivo de este artículo es incidir sobre la continuidad entre el análisis aristotélico de las pasiones y la comprensión de los afectos por parte del psicoanálisis freudiano y, en especial, lacaniano como efectos del lenguaje sobre el cuerpo. Para ello se atenderá en primer lugar a ciertos pasajes de la Ética a Nicomáco, de la Retórica y del De Anima de Aristóteles donde las pasiones son relacionadas con el lenguaje. En segundo lugar se atenderá al concepto de pulsión de Freud, basado en la distinción entre un afecto y una representación. Finalmente, se presentará la comprensión lacaniana del afecto a partir de textos de su seminario La angustia (1962-63), Radiofonía (1970) y Televisión (1972).

Palabras clave: afectos, psicoanálisis, Lacan, Freud, Aristóteles, pasiones.
\end{abstract}

\begin{abstract}
The aim of this paper is to stand up the continuity between Aristotelian analysis of passions and the understanding of afections by Freudian and especially Lacanian psychoanalysis as effects of language on the body. For this we first attend to certain passages in the Nicomachean Ethics, Rhetorics and of Aristotle's De Anima where passions are related to language. Secondly we shall address Freud's concept of pulsion, based on the distinction between affect and representation. Finally, the Lacanian understanding of affect is presented from his seminar The Anguish (1962-63), Radiophony (1970) and Television (1972).
\end{abstract}

Keywords: affections, psychoanalysis, Lacan, Freud, Aristotle, passions.

\section{Las pasiones de Aristóteles}

En el segundo libro de la Ética a Nicómaco Aristóteles distingue tres fenómenos en el dominio de lo anímico: 'pasión', 'facultad' o 'modo de ser'. En lugar de ofrecer una definición de la pasión proporciona un listado de ellas, añadiendo que puede ser considerado pasión todo aquello que vaya acompañado de placer o dolor ${ }^{1}$.

1 «Entiendo por pasiones, apetencia, ira, miedo, coraje, envidia, alegría, amor, odio, deseo, celos, compasión y, en general, todo lo que va acompañado de placer o dolor» (Ética a Nicómaco, 1105b, 20; Aristóteles 2007, 48). Aristóteles sigue el mismo procedimiento en la Ética a Eudemio: «Llamo pasiones a lo que sigue: indignación, 
Esta referencia al placer y al dolor se aclara si se recuerda que Aristóteles tiene seguramente en mente los dichos de Platón en torno a las pasiones. En el Filebo, en el contexto de un estudio del placer, Platón distinguía entre:

- mezclas de placeres y dolores puramente del cuerpo. Por ejemplo, un picor, evidentemente antes de que se convierta en una sarna pero más allá de ser un mero cosquilleo.

- mezclas de placeres y dolores que afectaban tanto al cuerpo como al alma. Por ejemplo, el deseo, que se manifiesta como un dolor o carencia a nivel del cuerpo pero como un placer o esperanza a nivel del alma.

- y mezclas de placeres y dolores específicas del alma². Estas últimas mezclas parece que son lo que Platón considera merecedor propiamente hablando del título de pasión, si se atiende a los ejemplos que pone: ira, miedo, añoranza, duelo, amor, celos y envidia ${ }^{3}$.

Si para Platón las afecciones eran algo recibido exclusivamente por el alma, en concreto, por su parte concupiscible, o si se acepta que la valentía es una pasión y no virtud, como mucho también por la parte irascible, para Aristóteles las pasiones son algo común al cuerpo y al alma, por lo que si insiste en destacar aquí lo material de la pasión probablemente se debe a su necesidad de contrariar un punto de vista que le parecería excesivamente espiritualista.

Aristóteles continúa en la Ética a Nicómaco añadiendo que las pasiones son algo que nos mueve, al contrario que las virtudes o los vicios, que son algo que simplemente nos dispone a movernos de determinado modo pero sin llegar a movernos ${ }^{4}$. Las pasiones ocupan para Aristóteles un lugar intermedio entre las facultades y los modos de ser o hábitos ya sedimentados ${ }^{5}$.

En la Ética a Nicómaco la pasión es tratada desde el punto de vista de algo a controlar mediante la virtud. En la Ética a Eudemio repite este mismo punto de vista, al afirmar que la conducta ética es el resultado de una buena conducción por parte de la razón de los deseos y de las pasiones ${ }^{6}$.

temor, vergüenza, apetito y, en general, todo lo que en sí mismo va, comúnmente, acompañado de placer o de dolor» (Ética a Eudemio, 1220b, 10-15; Aristóteles, 2007, 250).

2 «Pues bien, hay mezclas relativas al cuerpo que se dan exclusivamente en los cuerpos, y las hay del alma sola, que se dan el alma; y también vamos a encontrarlas dándose en el alma y en el cuerpo, dolores mezclados con placeres, llamados en conjunto unas veces placeres y otras dolores» (Filebo, 46b-c; Platón, 2007b, 84).

3 «Ira, miedo, añoranza y duelo, amor, celos y envidia, y todo lo semejante, ¿no los tienes como pesares del alma sola?» (Filebo 47e; Platón 2007b, 86).

4 «Finalmente, por lo que respecta a las pasiones, se dice que nos mueven, pero en cuanto a las virtudes y vicios se dice no que nos mueven, sino que nos disponen de cierta manera» (Ética a Nicómaco, 1106a, 7; Aristóteles, 2007, 49).

5 Gardiner considera que las pasiones de Aristóteles afectan exclusivamente al alma: «[...] and although the corresponding term 'psychic passions' does not occur, it seems to be implied in the description of the passions in the Rhetoric that they are what in the discussion of pleasure Aristotle called pleasures (and pains) of the soul» (Gardiner, 1919, 17).

6 «Pues si hablamos de él en cuanto ser humano, es necesario que posea la facultad de razonar como principio y con vistas a su conducta, esta facultad de razonar dirige no la razón, sino el deseo y las pasiones; por consiguiente, el ser humano debe necesariamente poseer estas partes» (Ética a Eudemio , 1220a, 5-10; Aristóteles, 2007, 248). 
Poco más adelante, añade Aristóteles que a las pasiones no les corresponde ninguna cualidad -constante, quiere decir- en el alma ${ }^{7}$. Al contrario que en la teoría platónica, en el alma aristotélica no hay una cualidad concupiscible y una cualidad irascible presentes en mayor o menor grado en todos los sujetos.

Lacan quien sostiene que lo mejor de la teoría aristotélica de las pasiones se encuentra en el libro segundo de la Retórica ${ }^{8}$. Ello se debe sin duda a que es allí donde Aristóteles explica la persuasión como la capacidad de provocar determinadas pasiones en los receptores del discurso, es decir, pone en relación discurso y pasión. En su introducción a la edición de la Retórica en la editorial Gredos, Quintín Racionero asegura que frente a la dialéctica, que se ocupa de los razonamientos en aquellas materias para las que no hay una ciencia determinada, la tarea de la retórica es estudiar las deliberaciones, instrumento de análisis de las cuestiones que atañen a la acción humana. La retórica busca fundamentación para determinadas decisiones prácticas que no pueden ser justificadas por parte de otras disciplinas más especializadas como la ética o la política, pero que pese a ello demandan un estudio serio. Ella aspira a organizar los discursos bajo una cierta «arquitectura razonable» o «cálculo racional» [logismós]. La retórica estudia, entonces, los motivos concretos de acción de los sujetos en aquellos campos donde no es posible encontrar una solución necesaria, sino tan solo probable.

Los argumentos del retórico tienen que basarse puramente en las razones y motivos expuestos en el discurso (capítulos I 1), pero a continuación afirmará que el control de los afectos es un elemento esencial para lograr la persuasión (capítulo I 2). Si el libro I se ocupa de la definición y división de la retórica, de los conceptos de lo bueno y de lo conveniente, de la oratoria y de lo justo e injusto, el libro II se abre con un estudio de cómo la persuasión debe tener en cuenta las pasiones.

Parece que el libro segundo fue el fruto de una revisión del texto original, o incluso el resultado de la adición de un texto que había sido redactado previamente por separado, puesto que el componente emocional de la pasión cobra de repente aquí un papel relevante que contrasta con el libro primero. Diógenes da noticia de tal texto en su catálogo de las

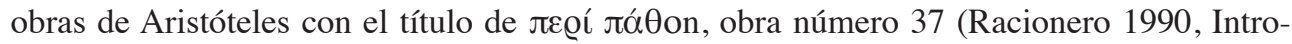
ducción, 109). Fortenbaugh niega que el catálogo de Diógenes sea un prueba aceptable de la escritura por parte de Aristóteles de un texto así y que esta autoría es un tema a seguir discutiendo, aunque él mismo la acepte como muy probable (1970, 61, nota a pié 44)

En todo caso, el libro II de la Retórica se ocupa de estudiar como dentro de cada pasión es posible encontrar la manera adecuada de utilizarla para mejor convencimiento del auditorio. Además de estudiar el carácter demostrativo de un juicio es necesario atender a cómo es posible conseguir convencer, conseguir que el oyente entre en una actitud favorable a aceptar la fuerza argumentativa de la demostración presentada mediante cierta operación de inclinación de sus afectos.

7 «Y no hay ninguna cualidad que les corresponda, pero sí con respecto a las facultades» (Ética a Eudemio 1220b, 10-15; Aristóteles, 2007, 250).

8 «Además para dejarlos con algo que les ocupe, les haré una sencilla observación. ¿Dónde es que Aristóteles trata mejor sobre las pasiones?. Pienso que incluso hay unos cuantos que ya lo saben: en el libro II de su Retórica.

Lo mejor sobre las pasiones está tomado en el hilo, en la red de la Retórica» (Lacan, 1961-62, 24). Citamos a Lacan en traducción propia de los textos franceses. 
La primera pasión estudiada es la ira, definida como un apetito de venganza una vez que se nos ha hecho alguna afrenta a nosotros o a alguien próximo. El orador debe (y puede) inclinar con su discurso a sus oyentes de tal forma que estos sientan ira hacia los oradores adversarios (Retórica 1380a, 1-5; Aristóteles, 2000, 187). La calma es un apaciguamiento de la ira que el retórico puede lograr mediante los argumentos adecuados, convenciendo de que las personas odiadas no son en realidad merecedoras de tal odio mediante diferentes argumentos (Retórica 1380b, 30; Aristóteles 2000, 192). Pero en realidad lo que Racionero

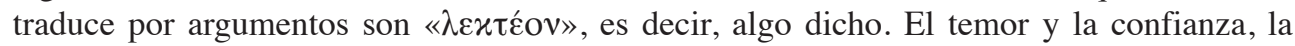
vergüenza y la desvergüenza y la prestación o no de favores le interesan a Aristóteles en la medida en que las argumentaciones persuasivas pueden provocar una u otra situación. En el caso del favor no se trata tan solo de que haya por medio algo material que es otorgado o no, sino de la disposición afectiva previa que inclina a una u otra situación. Una vez que se ha analizado quien es el sujeto merecedor del favor los argumentos deben ser preparados o dispuestos de la manera más adecuada para mover el ánimo de los oyentes (Retórica 1385a, 29-35; Aristóteles 2000, 218). La compasión se produce en nosotros en aquellas situaciones en que más estamos persuadidos de que nos podría afectar el mal que afecta al otro, de manera que la retórica ocupa un lugar preeminente como posible factor para despertar este afecto. En el caso de la indignación, la conclusión es de nuevo la misma: el discurso puede predisponer a los que juzgan a considerar a ciertos indignos como dignos de compasión y viceversa. El discurso [lógos] «predispone» o «dispone» a los oyentes a una u otra pasión. La envidia es también algo que puede variar según la disposición en que los oyentes sean colocados por el orador. Tras estudiar la emulación, el deseo de imitar a alguien para disfrutar de los bienes de los que él disfruta, se cierra el estudio de las pasiones y de la manera en que los argumentos pueden modificarlas. Puede concluirse entonces que en la Retórica de Aristóteles la pasión es tratada como algo que puede verse afectado por el discurso, de manera tal que provoque unos $\mathrm{u}$ otros afectos.

Al comienzo del De anima Aristóteles sostiene que es enormemente complejo decidir si los afectos son algo exclusivo del alma o si afectan al compuesto de alma y cuerpo. La primera constatación es que el alma no suele padecer sin que el cuerpo sea también afectado. El argumento decisivo parece ser que en caso de que existiesen afecciones que afectasen exclusivamente al alma habría que suponer a contra gusto que esta puede existir por separado. La conclusión es que las afecciones son algo a lo que les es intrínseca la materia9 ${ }^{9}$, es decir, algo del cuerpo.

Aristóteles duda acerca de si el encargado del estudio de las afecciones debe ser el dialéctico o el físico. Mientras que el primero llevaría a cabo definiciones que en la actualidad calificaríamos como 'psicológicas', definiciones del orden de las que recogen las Éticas o la Retórica -por ejemplo, la definición de la ira como una venganza-, el físico se limitaría a describir las reacciones del cuerpo (el corazón, la sangre). Es por ello por lo que la pasión debe interesar a ambos campos del saber, de manera tal que el buen filósofo del alma tendrá que ser físico y dialéctico al mismo tiempo.

9 «Por consiguiente, y si esto es así, está claro que las afecciones son formas inherentes a la materia» (De anima I, 1, 403a25-26; Aristóteles, 2007, 359). 
En un texto clásico sobre la cuestión Fortenbaugh apunta que la afección aristotélica tiene un componente cognitivo importante que la aparta del campo de lo meramente irracional. La afección aristotélica sería todo lo contrario de un 'impulso ciego' o un 'reflejo automático' ${ }^{10}$ como sucede con el hambre o la sed. La afección aristotélica no se reduciría a ser una mera excitación corporal, puesto que las 'emociones' reconocen además del estado del sujeto que las padece, un objeto o persona hacia el que se dirigen y una serie de motivos ${ }^{11}$. Por lo tanto, se puede concluir que, sea en su versión más 'encantadora' sofística, sea en su versión más 'razonante', la pasión aristotélica posee siempre un componente cognitivo que hace referencia al lenguaje.

\section{El afecto en la teoría freudiana}

\subsection{La teoría de la conversión histérica de los afectos (de 1894 a 1915)}

En un primer momento, la noción de afecto es adoptada por Sigmund Freud tal y como esta es tratada por la tradición psicológica alemana. Wilhelm Wundt (1832-1920) habla de cierto sentimiento inicial causado por una impresión exterior o un proceso psíquico interior que se desenvuelven hasta constituir un afecto, y al que posteriormente se le vendría a asociar una representación (Wundt 1998, 204). Freud asume esta distinción conceptual entre representación y afecto. En sus Estudios sobre la histeria de 1893 sostiene que el objetivo final del psicoanálisis es liberar el afecto penoso que acompañó en un primer momento a la representación de una escena traumática negativa y que en su momento no pudo ser liberado. El afecto que acompaña a una escena desagradable, si no se produce algún tipo de descarga, puede enquistarse. Las descargas más efectivas son las descargas corporales: por ejemplo, unos lloros, un enfado, etc. (Freud 1893, 87).

En Las neuropsicosis de defensa (1894) Freud propone que las parálisis histéricas parten de una escena traumática, tomando como paradigma de ella algún tipo de violencia sexual infantil sufrida por el futuro sujeto histérico por parte de algún adulto. Después, esta representación va a ser reprimida, formando lo que el neurólogo francés Pierre Janet (1859-1947) había ya denominado «estado hipnoide»: un contenido de la conciencia que permanece separado del resto. El afecto asociado a este contenido no puede ser liberado hasta que se produce algún tipo de operación de abreacción mediante el habla en una sesión de psicoanálisis porque el origen del síntoma histérico se debe a un afecto que no ha encontrado una descarga adecuada y se ha convertido en algo corporal. La cura psicoanalítica es pensada en esta época por Freud, sea mediante la hipnosis, sea mediante la palabra, como el intento por volver a traer a la conciencia las huellas mnémicas, los recuerdos de la representación reprimida, buscando conseguir una abreacción del afecto que una vez separado de la representación a la que estaba originalmente unido ha ido a depositarse

10 «blind impulse», «automatic reflex» (Fortenbaugh, 1970, 61).

11 «And finally, this emphasis upon cognition helps to distinguish emotions from bodily drives and so helps to develop and an adequate moral psychology» (Fortenbaugh, 1970, 42). «The mention of objects («at whom», tísin) and grounds (épi poíois) is important; it strongly suggests that Aristotle does not dissociate cognition from emotion. Unless Aristotle is confused, he does not conceive of emotions simply as inner (mental or bodily) feelings or sensations» (Fortenbaugh, 1970, 54). 
sobre el cuerpo. La rememoración sólo resulta terapéuticamente eficaz si el recuerdo del acontecimiento implica la reviviscencia del afecto que estuvo ligado a aquel en su origen.

\subsection{El afecto como energía de la pulsión}

La noción de afecto pasará a ser comprendida posteriormente como la parte energética de la pulsión. En uno de los textos metapsicológicos, La represión (1915), distingue entre el afecto y el quantum o cantidad de afecto [Affektbetrag] o energía pulsional ${ }^{12}$. El afecto sería la traducción subjetiva de una cierta cantidad de energía pulsional, de manera tal que al igual que la noción de pulsión, el afecto estaría operando como un concepto bisagra entre lo puramente corporal y lo psíquico.

Cuando analiza la pulsión Freud distingue entre la idea o representación y la cantidad pulsional o afectiva ${ }^{13}$. Así es posible comprender como puede darse el caso de que aparezca un afecto para el que no se encuentra ninguna explicación razonable en relación al medio exterior, una respuesta a la que no parece corresponder ningún estímulo coherente externo. Por ejemplo, en la angustia. En estos casos, Freud afirma que la representación originalmente asociada al afecto falta y aparece otra en su lugar que no parece guardar de entrada ninguna relación lógica con ella.

El afecto no se halla necesariamente ligado a la representación; su separación (afecto sin representación, representación sin afecto) permite que cada uno de ellos siga un destino diferente. El afecto freudiano es algo a pensar como algún tipo de cantidad o carga eléctrica que puede recorrer las representaciones, desplazarse a través de ellas ${ }^{14}$.

Dicho de otro modo, la teoría freudiana distingue entre una representación/representante y una carga afectiva o cantidad de excitación: la percepción de un perro y la angustia que

12 «En las consideraciones anteriores tratábamos la represión de un representante pulsional y entendíamos por tal una presentación o un grupo de representaciones que estaba investido por parte de la pulsión con una determinada cantidad de energía psíquica / (Libido, interés). La observación clínica nos obliga a descomponer ahora lo que habíamos aprehendido como una unidad, porque nos muestra que hay que considerar, junto a la representación, algo distinto, algo que representa a la pulsión, y que sufre un destino de represión que puede ser totalmente diferente del de la representación. Para designar este otro elemento del representante psíquico se ha establecido el nombre de quantum de afecto [Affektbetrag]; corresponde a la pulsión, en tanto que ella se ha desprendido de la representación y encuentra una expresión conforme a su cantidad en procesos que la sensación puede notar en tanto que afectos. En adelante, en la descripción de un caso de represión, habrá que investigar por separado lo que ocurre con la representación y lo que ocurre con la energía pulsional ligada a ella» (Freud 1915a, 254-55).

13 «El estado de cosas es realmente aquí otro. En primer lugar puede suceder que se perciba una moción de afecto o sentimiento, pero no sea reconocida correctamente. Habiendo sido reprimido su representante propio, ella fue obligada a enlazarse a otra representación, y la conciencia la toma ahora por la manifestación de esta última. Cuando restablecemos la conexión correcta, llamamos «inconsciente» a la moción de afecto originaria, aunque su afecto nunca haya sido inconsciente y sólo su representación haya sucumbido a la represión. La utilización de las expresiones «afecto inconsciente y sentimiento inconsciente» se refiere a los destinos del factor cuantitativo de la moción pulsional a consecuencia de la represión (véase el apartado sobre La represión)» (Freud 1915b, 276).

14 «Por último, expondré en pocas palabras la representación auxiliar de la que me he servido en esta exposición de las neurosis de defensa. Hela aquí: en las funciones psíquicas cabe distinguir algo (monto de afecto, suma de excitación) que tiene todas las propiedades de una cantidad -aunque no poseamos medio alguno para medirla-; algo que es susceptible de aumento, disminución, desplazamiento y descarga, y se difunde por las huellas mnémicas de las representaciones como lo haría una carga eléctrica por la superficie de los cuerpos. 
provoca, en el caso de una fobia. Lo que apunta Lacan es que la representación/representante es móvil e intercambiable. El sujeto puede ser representado por diferentes representaciones, permaneciendo siempre más allá. Por ejemplo, la percepción de un perro remite a otra representación escondida en la que hubo una situación de maltrato para un sujeto.

Es importante señalar que los afectos propiamente dichos no son nunca inconscientes. La representación reprimida pasa a formar parte del sistema inconsciente; pero al afecto reprimido no le corresponde en este plano más que una especie de rudimento, una cierta moción pulsional que solo en algunos casos termina por desenvolverse hasta manifestarse como sentimiento, como afecto propiamente dicho (Freud 1915b, 277).

\section{El afecto como efecto del lenguaje sobre el cuerpo en la enseñanza de Jacques Lacan}

\subsection{La angustia como afecto que no engaña}

Aunque la teoría psicoanalítica de Jacques Lacan varía profundamente desde sus inicios hasta el final, su concepción de los afectos no cambia y los entiende siempre como efectos del lenguaje sobre el cuerpo. Uno de los afectos de mayor afección del cuerpo y en donde se puede comprobar la eficacia de esta teoría sería la angustia ${ }^{15}$.

De 1953 a 1981 Lacan imparte un curso semanal de enseñanza del psicoanálisis en París. El Seminario número X (1962-1963) está dedicado por entero a la angustia, que es para Lacan el afecto por excelencia. Hacia el final de la primera clase de este seminario Lacan recuerda la afirmación de Freud acerca de que no tendría sentido la defensa de que existen afectos inconscientes: los afectos nunca están reprimidos, sino desplazados. Sería un contrasentido afirmar que existe algo así como la «tristeza inconsciente».

Por otra parte, frente a ciertas teorías que consideran que las manifestaciones afectivas tienen algún tipo de privilegio en la expresión de la verdadera situación del sujeto, Lacan afirma que a través del afecto no se nos da el ser en su inmediatez o el sujeto en su forma bruta. Solo aparentemente el afecto es un lugar privilegiado de manifestación de la verdad del sujeto. Parece que los afectos no pueden engañar -la tristeza es tristeza, el malhumor es malhumor-, mientras que todo aquello mental, intelectual o lingüístico es el terreno donde pueden aparecer los equívocos. Pero sin embargo, aunque el afecto nunca pueda ser reprimido, los representantes que lo amarran o se unen a ese afecto -los 'significantes' en la terminología de Lacan- pueden ser objeto de represión. Es decir, un afecto de alegría será siempre sentido como alegría, pero puedo aparecer desplazado con respecto a la escena que realmente lo ha causado ${ }^{16}$.

Es posible utilizar esta hipótesis, que por lo demás ya está en la base de a teoría de la «abreacción» en el mismo sentido en que el físico emplea el supuesto del fluido eléctrico que corre. Provisionalmente está justificada por su utilidad para resumir y explicar múltiples estados psíquicos» (Freud 1894, 74).

15 «...] porque un punto que yo quería señalar es que sencillamente Lacan siempre va a considerar el Afecto como un efecto del significante sobre el cuerpo. Primer punto sobre en el cual diría no hay mucha modificación. En este punto Lacan, no hay duda, vamos a ver, muy freudiano. Entonces un significante produce un efecto que es el Afecto, pero por eso considero que el seminario central es el Seminario X» (Rabinovich, 2011, clase 1, 2).

16 «Por el contrario, lo que yo he dicho del afecto, es que él no está reprimido. Esto, lo dice Freud al igual que yo. Él está desamarrado, va a la deriva. Se lo encuentra desplazado, loco, invertido, metabolizado, pero no reprimido. Lo que está reprimido son los significantes que lo amarran» (Lacan, 1962-63, 24). 
La posición del psicoanálisis lacaniano pasa por una separación con respecto a cualquier teoría general de los afectos, a cualquier psicología que valga. En su opinión los psicólogos son aquellos que se ocupan de la psyché y la psyché es una «realidad irreal» ${ }^{17}$, mientras que el psicoanálisis debe tratar con algo mucho más inmediato, aplicado y práctico que es el deseo.

En el capítulo II de este mismo seminario La Angustia Lacan rechaza dos vías para estudiar los afectos y se queda con una tercera:

- en primer lugar, la vía del catálogo, que consistiría en llevar a cabo una recolección de opiniones acerca de qué quiere decir el término afecto. Su concepto de angustia no podría ser comprehendido en ninguna de estas opiniones actuales o de la antigüedad.

- una segunda vía pasaría por emplear una cierta analogía: la angustia pensada en la biología, en la sociología, en la cultura, pero esta no podría explicar la experiencia de la angustia en el psicoanálisis, que es especialmente particular.

La vía correcta sería una vía que Lacan denomina aquí «función de la llave» (Lacan, 1969-70, 30) y que consiste fundamentalmente en insistir en la relación entre la palabra y el afecto, en este caso, entre el lenguaje y la angustia ${ }^{18}$.

La angustia que originariamente despierta una determinada escena traumática puede pasar a desplazarse y situarse sobre otra escena que guarda con aquella algún tipo de relación inconsciente. Por ejemplo, en el mecanismo que desencadena una fobia un elemento aparentemente inofensivo se convierte en angustiante porque guarda una relación inconsciente con otro elemento que ha sido angustiante para el sujeto: la percepción de un perro en los fóbicos a dicho animal no despierta una fobia por sí mismo sino porque está relacionada con otra situación que ha sido traumática para el sujeto.

En este sentido, incluso el pensamiento tiene para Lacan algo del orden del afecto, porque también detrás de un pensamiento se esconde siempre otro, también él siempre está como desplazado, es la capa superficial de algo otro ${ }^{19}$. Es por ello por lo que todo acercamiento a los afectos debe pasar por un estudio que ponga en juego el plano del lenguaje: más allá de lo puramente afectivo, siempre se ven acompañados por un componente representacional en el que se producen intercambios y desplazamientos. Ahora bien, al mismo tiempo, el seminario $\mathrm{X}$ insiste en que la angustia se distingue del resto de afectos por ser aquel que no engaña ${ }^{20}$. Para Lacan la angustia es el afecto que siente el sujeto cuando se ve enfrentado al deseo.

17 «No les desarrollo una psico-logía, un discurso sobre esta realidad irreal que llaman la psyché, sino una praxis que merece un nombre, erotología. Se trata del deseo» (Lacan, 1969-70, 24).

18 «Lacan se pregunta en este Seminario cómo abordará la cuestión, mientras valida, explícitamente, que la angustia es un afecto, que se la experimenta, se la siente como tal. Él distingue tres modos de abordar el problema, para rechazar dos y elegir uno. Son, si se quiere, las tres $c$, que enumera y etiqueta con palabras de las que es la inicial. Rechaza catalogar los afectos, como rechaza clasificarlos, y elige esta aproximación que califica de clave. Rechaza las enumeraciones, incluso ordenadas, incluso jerarquizadas, y ofrece en cambio como vía de acceso algo de un orden distinto» (Miller, 2007, 38).

19 «El pensamiento no es una categoría. Diría casi que es un afecto. Aunque no fuese más que por decir que es lo más fundamental bajo el ángulo del afecto» (Lacan, 1969-70, 176).

20 «A partir de algo que es la angustia son posibles todas las maniobras, y al fin de cuentas se trata de lo que esperábamos, la verdadera sustancia de la angustia, «lo que no engaña», lo fuera de duda, pues no se dejen 
En el curso de sus seminarios V (Las formaciones del inconsciente, 1957-1958) y VI (El deseo y su interpretación, 1958-1959), Lacan construye un esquema de flechas donde relaciona principalmente el lenguaje y el deseo (Lacan, 1957-58, 510). Este esquema es conocido como grafo del deseo y de él se desprende que el deseo para Lacan es el resultado de una articulación de la demanda en el lenguaje. Cuando el niño demanda alimento, se ve obligado a formular esta demanda en el lenguaje -los balbuceos son lenguaje- y sobre esta formulación transluce o se puede interpretar un deseo. El deseo no es, por lo tanto, ni una necesidad natural ni una demanda. Se distingue radicalmente de la necesidad, puesto que los gritos del niño en busca de comida deben ser formulados en un lenguaje que lo precede, deben ser asumidos como demanda por otro sujeto -la madre o el padre-. La necesidad solo significa algo porque se articula en el lenguaje, porque el sujeto se introduce en el campo de la palabra y del lenguaje. Más allá todavía se aparece el deseo, cuando el sujeto apunta con su demanda a un objeto que es causa de su deseo. El objeto-causa del deseo es para Lacan un objeto que falta y al mismo tiempo actúa como causa, moviliza el deseo.

Siguiendo estas coordenadas, Lacan afirmará que existe una insatisfacción esencial al deseo, puesto que a este le falta siempre el objeto: el objeto del deseo se muestra como un objeto ausente, inalcanzable, como una falta [manque]. Si en un primer momento de su enseñanza Lacan sostiene que el objetivo central del psicoanálisis es la destrucción de los complejos (complejo de destete, complejo de intrusión o celos con respecto a otro hermano o rival ante la madre, complejo de Edipo), durante una segunda época -que no será la últimapasa a considerar que lo esencial es decir y delimitar el objeto-causa del deseo.

El afecto de la angustia surge cuando algo viene a aparecer en el lugar semivacío que ocupa habitualmente el objeto-causa del deseo. Para que el deseo movilice al sujeto, es necesario que le falte algún objeto. Si no hay falta, es entonces cuando surge la angustia. La angustia lacaniana no es la señal de una falta sino la carencia de ese apoyo indispensable que es la falta, es la señal de la falta de esta falta del objeto-causa del deseo, es decir, es señal de la amenaza de que se presenten los objetos del deseo que habitualmente faltan. Todo esto implica que el objeto de la angustia es un objeto al menos en parte construido en el lenguaje, es decir, que «medio ser» de la angustia es de naturaleza lingüística.

\subsection{La incidencia del lenguaje sobre el cuerpo en la teoría de los afectos de Lacan}

Si en el seminario sobre La angustia se pone de manifiesto que Lacan quiere relacionar la angustia con el lenguaje, en la última enseñanza de Lacan el intrincamiento entre lenguaje y afecto se extenderá desde la angustia al resto de los afectos.

El texto Radiofonía consta de las siete respuestas que Lacan ofrece a otras tantas preguntas durante una entrevista para una emisora de radio belga en 1970. La segunda pregunta gira en torno al significado del concepto de estructura en psicoanálisis y a lo largo

\footnotetext{
llevar por las apariencias: no porque les parezca clínicamente sensible el lazo entre la angustia y la duda, la vacilación, el llamado «juego ambivalente» del obsesivo, angustia y duda son la misma cosa.» (Lacan, 1961-62, 92). «En este sentido fue que aventuré ante ustedes la formula de que, de todas las señales, la angustia es aquélla que no engaña» (Lacan, 1961-62, 202). «La angustia, les he dicho que hay que definirla como aquello que no engaña, precisamente en tanto que todo objeto le escapa. La certeza de la angustia está fundada, no es ambigua» (Lacan, 1961-62, 252).
} 
de la respuesta Lacan lleva a cabo un peculiar ejercicio de ontología en el que distingue varios niveles. En primer lugar tenemos el lenguaje y es gracias al lenguaje como podemos hablar de un cuerpo: el lenguaje permite que se constituya el cuerpo en sentido habitual. Es decir, es gracias a una cierta operación del lenguaje como comenzamos a tener un cuerpo organizado en brazos, piernas, etc. Para marcar el carácter de antecedencia del lenguaje sobre el proceso de constitución de un cuerpo singular, Lacan afirma que el lenguaje es algo consistente, algo sólido de por sí: sólo se puede hablar de un cuerpo con brazos, piernas, manos... si esos significantes, esas palabras estaban ya ahí previamente. Es por ello por lo que se puede afirmar que es el primer cuerpo -el del lenguaje-, el que le permite al segundo -el cuerpo en sentido habitual- incorporarse, constituirse como tal cuerpo.

El cuerpo no es algo que para ser tal tenga que estar vivo, porque también recibe la calificación de cuerpo un cuerpo muerto. El cuerpo nunca se transforma en carroña una vez que el lenguaje lo ha creado, sino que este acto creador tiene efectos para siempre: un cadáver en una tumba será para siempre un cadáver. Lo primero que necesita el cuerpo para ser cuerpo es de una operación lingüística que lo instituye como tal de manera definitiva ${ }^{21}$.

Ahora bien, en este esquema todavía falta precisar cuando surgen los afectos. Cuando la estructura, es decir, el lenguaje, se incorpora, genera el afecto. Los afectos deben ser entendidos como el resultado de la incorporación de la estructura, del lenguaje, sobre el sujeto. La conclusión a retener es que los afectos no provienen del cuerpo segundo, del cuerpo en sentido habitual -no son, por ejemplo, un dolor físico, algo que tiene que ver con el organismo-, sino que ellos proceden de un momento anterior donde juega un papel central el lenguaje.

Dos años más tarde, en Televisión (1972), retoma el tema de los afectos. De entrada Lacan descarta cualquier teoría de los afectos que los piense como una especie de maniobra de la psique para readaptarse al mundo exterior. No tiene sentido defender que existen afectos «adecuados» en el sentido de que ante una situación externa la psique reaccionaría provocando la situación anímica más apropiada. Probablemente tiene en mente a Sartre y su Bosquejo de una teoría de las emociones (1939), donde los afectos son pensados como un mecanismo de regulación de la correlación entre el yo y el mundo con el objetivo de recuperar el equilibrio homeostático habitual entre estos dos polos. Sartre pone de relieve la función afectiva de la conciencia que siente el mundo como emocionante: cada una de las emociones es un modo diferente de eludir una dificultad, de manera que el afecto tiene la misión de recuperar la armonía inicial entre mundo y sujeto. Uno de los problemas de esta concepción 'funcional' de los afectos es que no permite explicar cuál sería la función de la angustia, que es un afecto absolutamente paralizante, totalmente afuncional ${ }^{22}$.

La teoría de la significación en el psicoanálisis de orientación lacaniana parte de la distinción básica de Saussure entre significante y significado para otorgarle un papel preponderante a la parte significante. Aplicando esta idea al campo de los afectos puede sostenerse que

21 «Quien no conoce el punto crítico en el que datamos el hombre, el ser parlante: la sepultura, sea donde, de una especie, se afirma que al contrario que cualquier otra, el cuerpo muerto guarda de ella aquello que le da al viviente su carácter: el cuerpo. Corpse permanece, no deviene carroña, el cuerpo que habita la palabra, que el lenguaje corpsifica» (Lacan, 1970, 409).

22 «[...] pues no se percibe para que podría servir la angustia en esa armonía natural a menos que se establezca un principio de clasificación del afecto que sea adecuado o inadecuado» (Miller, 1986, 153). 
el afecto es un significante para el que es necesario proceder a la búsqueda del significado. Que los afectos no se tomen como verdaderos sino que hay que verificarlos, quiere decir que ellos no valen de entrada por sí mismos, no son evidentes.

Es por ello por lo que el psicoanálisis no va a examinar si ante una determinada situación el sujeto siente lo que corresponde, sino que indagará acerca de que es lo que hay detrás de un afecto y que se esconde para un sujeto concreto y particular detrás de un determinado afecto. El psicoanálisis lleva a cabo una verificación del afecto, que no es una autentificación. No se trata de corroborar que un afecto está en proporción a determinada situación vivida por el sujeto, sino de la búsqueda de la verdad concreta y particular del sujeto que se encuentra detrás de un afecto determinado, del descubrimiento del significante o representación reprimidas que se encuentran para ese sujeto tras determinado afecto.

Lacan reivindica la noción clásica de la pasión de un Platón o de un Tomás de Aquino como antecesoras de la línea en la que se sitúa su teoría de los afectos. En el caso de Aquino se trata del capítulo LXVIII del tratado Pasiones del alma, que forma parte del libro IV de la Suma teológica (Miller, 1988, 161). Si Platón puede clasificar las distintas pasiones (racional, irascible, concupiscible) relacionándolas con diferentes partes del cuerpo (cabeza, corazón, subcorazón), ello se debe a que hay un cuerpo que es afectado por la estructura, por el lenguaje. Por otra parte, y como novedad, en estas páginas de Televisión Lacan se encuadra a sí mismo en una tradición secular, originada en Aquino, que entiende las pasiones o perturbaciones del alma bajo el paradigma virtud/pecado.

Así, por ejemplo, la tristeza deja de ser pensada como un estado del alma, para pasar a ser pensada como una cierta falta o flaqueza moral. Más que de depresión y de algo que afectaría al alma, de un estado del alma, se trata de un problema a nivel del pensamiento, sin olvidar que pensamiento y lenguaje son sinónimos para Lacan ${ }^{23}$.

Otra manera de decir lo anterior es que los afectos deben ser interpretados como variaciones del humor provocadas por los distintos modos en que el lenguaje atrapa al objeto-causa del deseo. En la tristeza hay una cierta cobardía o flaqueza con respecto al propio deseo, un desfase entre lo que se dice y lo que inconscientemente se desea. El sujeto no se pone de acuerdo con su deseo. La tristeza consiste en cierta imposibilidad para decir bien, en el hecho de que hay algo exterior al saber, a la palabra, con lo que el sujeto no es capaz de ponerse en «resonancia» (Miller 1988, 162).

En el polo opuesto a la tristeza se encontraría el «gay sçavoir» (Lacan, 1972, 526). Sçavoir es la antigua grafía de savoir con el añadido final del término latino «scire»: cortar, separar que es precisamente de lo que está hablando Lacan en estos momentos: de un saber alegre que haga función de corte con la tristeza anterior. Se trata de algún tipo de saber que consiste en la virtud, no de comprender mejor ni de disfrutar descifrando los entresijos del inconsciente, sino de atreverse a llegar hasta el límite del sentido, el límite de lo comprensible. Este saber alegre consiste en la alegría de decir bien todo aquello que se puede decir.

23 «En esto tocamos la interpretación lacaniana como falta del pensamiento, que introducía toda esta clínica según la cual el depresivo sufre, ciertamente, en su cuerpo, pretende también sufrir en su alma (es un «estado del alma») cuando en realidad comete una falta en su pensamiento. Es decir, él se trata mal, en todo el sentido de la palabra: dice mal de sí mismo, mal-dice de él. Esta es la 'ética del mal-decir' (de sí) en la cual el deprimido se abisma» (Regnault, 2005). 
Otro ejemplo de afecto ofrecido por Lacan es la beatitud, el hecho de que un sujeto se siente pleno, carente de nada, y no gracias a otro sujeto, sino a Dios, que colma plenamente aquello a lo que aspira. $\mathrm{O}$ el aburrimiento, resultado de la reducción o asimilación de todo aquello que le ofrece el exterior al sujeto a algo igual y homogéneo al sujeto (de «ennui» -aburrimiento- Lacan se pasa a «unien»-uniano-), y que aparece cuando se siente que no hay nada que el sujeto necesite. El mal humor es pensado como el resultado de que el sujeto no se siente a gusto en el lenguaje, de que no encuentra «alojamiento» en el lenguaje, algo que provoca que cierto grado de mal humor es algo normal, puesto que entre el sujeto y el lenguaje siempre hay una barrera ${ }^{24}$.

En definitiva, se hace patente, en primer lugar, que los afectos lacanianos no son meras emociones, cambios emocionales temporales resultado de la acomodación del sujeto a variaciones que tienen lugar en la realidad exterior, sino que los afectos hacen referencia a algo más estable y más cercano al terreno de las pasiones que al de las emociones. Los afectos no son una simple respuesta mecánica-instintiva-animal a algo exterior, sino que el afecto que vaya a aparecer en cada situación llevará la marca del sujeto, pondrá en juego algo de lo más íntimo de ese sujeto ${ }^{25}$.

Es cierto que el cuerpo se manifiesta a través de los afectos, pero esto no permite afirmar que el afecto sea como la voz del cuerpo, sino que más bien el cuerpo -o el alma, si se quiere, aunque siempre entendida como el pensamiento- son una especie de instrumentos del lenguaje.

\section{Conclusión}

La tesis de este artículo es que el psicoanálisis de orientación lacaniana se aparta de cualquier psicología de las emociones y defiende la conveniencia de pensar el afecto en continuidad con la noción clásica de pasión, pensando esta como el efecto del lenguaje sobre el cuerpo. Para ello Lacan reivindica una tradición que parte de Aristóteles y que rechaza que la pasión puede ser comprendida a partir del organismo. Que la Retórica de Aristóteles insista en la capacidad del discurso para modificar las pasiones del sujeto, le da pié para pensar los afectos como el resultado de los efectos sobre el cuerpo del lenguaje. El afecto se comprende como algo que sufre el cuerpo, pero cuyo origen está del lado del lenguaje.

El psicoanálisis distingue entre cuerpo y organismo: el cuerpo es el organismo una vez que ha sido afectado por el lenguaje, de manera que no es posible afirmar que el sujeto vive exclusivamente en su organismo, sino que él lo hace también en un cuerpo.

Los enfoques biologicistas actuales aspiran a convertir la pasión en algo puramente cerebral en un intento por eliminar la presencia del sujeto a cualquier precio. El último intento pasa por buscar las raíces de cualquier comportamiento a nivel cerebral. La invasión de lo neuro- en el campo de las humanidades y las ciencias sociales es insultante y preocupante:

24 «Así el afecto llega a un cuerpo cuya peculiaridad consiste en habitar el lenguaje -me pavoneo aquí de plumas que se venden mejor que las mías-, el afecto, digo, de no encontrar alojamiento, al menos no de su gusto. Eso se llama pesadumbre [morosité], mal humor también» (Lacan, 1972, 527).

25 «La orientación lacaniana implica, pues, distinguir las emociones, de registro animal, vital, en su aspecto de reacción a lo que tiene lugar en el mundo, de los afectos en tanto que son del sujeto» (Miller, 1988, 160). 
neuropedagogía, neuroestética, neurociencia, neurocomunicación, neuroderecho ${ }^{26}$. Por ejemplo, parece que no tardará demasiado en ser empleada la neuroimagen funcional en los juicios para detectar cuando una persona miente o dice la verdad. Por su parte, la neuropsiquiatría pretende reducir la tristeza a ser una sustancia cerebral -la serotonina-, más allá del alcance del sujeto. Finalmente, lo que une a todas estas disciplinas es un extraño afán por eliminar el papel y la responsabilidad del sujeto en todas estas cuestiones. Movidas por un antigüo dualismo cuerpo-alma, en realidad, organismo-alma, ellas proponen que se pueden llevar a cabo modificaciones sobre el alma a base de modificaciones directas sobre las sustancias del organismo (Klainer, 2002). Así, un aumento de la concentración de serotonina cerebral tendría como consecuencia ideas y sentimientos alegres, independientemente de la voluntad y del deseo del sujeto. Lacan parte de otros supuestos y con una noción de cuerpo diferente, destaca la importancia del papel del lenguaje como aquel elemento intermedio entre el organismo y el cuerpo. Sin duda, los afectos no son meras palabras y se sienten, pero no al nivel de las sustancias, al nivel del organismo, sino de un cuerpo que está ya pasado por el filtro del lenguaje: el sujeto no se queja de una carencia de serotonina, sino de tal y tal cuestión concreta que lo entristece.

Así, el psicoanálisis no se ve convertido en una operación puramente intelectual, sino que su campo de trabajo es el lenguaje, que está, como los afectos, a medio camino entre lo emocional y lo intelectual. El discurso tiene efectos sobre el cuerpo y los psicoanalistas intentan controlar estos efectos provocando otros mediante un trabajo que pasa por la palabra, aunque es evidente que esto no agota toda la operación analítica, sino que esta tiene aún una vertiente epistémica que requiere más tiempo y trabajo. Es por ello por lo que Lacan se burla de aquellos psicoanalistas que pretenden reducir su tarea a que sus pacientes tengan buenos sentimientos, casi podríamos decir, buenas sensaciones (Lacan, 1971-72, 228). Las mejoras a nivel afectivo provenientes de un psicoanálisis serán siempre el resultado 'indirecto’ de la elaboración de un saber y un bien-decir del sujeto acerca de su deseo.

\section{Bibliografía}

Aristóteles (1953), Retórica, Madrid, Centro de Estudios políticos y constitucionales, $2003^{6}$. Edición a cargo de Antonio Tovar.

Aristóteles (2000), Retórica, Madrid, Biblioteca Básica Gredos, Gredos, 2000. Edición a cargo de Quintín Racionero.

Aristóteles (2007), Ética nicomáquea. Ética eudemia. Acerca del alma, Barcelona, Biblioteca Gredos, RBA, 2007.

Fortenbaugh, W. (1970), «Aristotle's Rhetoric on Emotions», Archiv für Geschichte der Philosophie, 52. Band, 1970, Heft 1, Walter de Gruyter\&Co, Berlin, pág. 41-70.

García, Germán (1998), «La pasión humana de entender las pasiones» en http://www.pagina12.com.ar/1998/98-12/98-12-21/psico01.htm. Gardiner, H. N. (1919), ,,The Psychology of the Affections in Plato and Aristotle. II. Aris-

26 «En conclusión: desde la teoría de los humores a la búsqueda de un gen para cada cosa, se prosigue la causa endógena de las pasiones. Por el contrario, desde el furor en Platón hasta la actividad que se enmascara en pasividad, es al sujeto en tanto efecto de su enunciación a quien nos dirigimos» (García, 1998). 
totle«, en The Philosophical Review, Vol. 28, No. 1 (Jan., 1919), ppág. 1-26. Published by: Duke University Press on behalf of Philosophical Review. En la web: http://www. jstor.org/stable/2178119.

Klainer, Estebán (2002), «Efectos de las sustancias en el cuerpo» en Boletín nº11. XVII Jornadas Anuales de la EOL, en http://www.eol.org.ar.

Lacan, Jacques (1938), «Les complexes familiaux dans la formation de l'individu» en Lacan, Áutres Écrits, Paris, Seuil, 2001, págs. 23-84.

Lacan, Jacques (1949), «El estadio del espejo como formador de la función del yo», en Lacan, Jacques, Écrits, Paris, Seuil, 1966, Volumen I, págs. 93-100.

Lacan, Jacques (1960), «Nota sobre la exposición de Daniel Lagache. Psicoanálisis y estructura de la personalidad», Paris, Seuil, 1966, Volumen II, págs. 647-684.

Lacan, Jacques (1957-58), Le Séminaire V, Les formations de l'inconscient, Paris, Seuil, 1998.

Lacan, Jacques (1969-70), Le Séminaire XVII, L'envers de la psychanalyse, Paris, Seuil, 1991.

Lacan, Jacques (1962-63), Le Séminaire X, L’angoisse, Paris, Seuil, 2004.

Lacan, Jacques (1970), « Radiophonie », Autres écrits, Paris, Seuil, 2001, págs. 403-447.

Lacan, Jacques (1972), « Télévision », Autres écrits, Paris, Seuil, 2001, págs. 509-545.

Miller, Jacques-Alain (1988), «A propósito de los afectos en la experiencia analítica» en Matemas, II, Buenos Aires, Manantial, págs. 147-164.

Miller, Jacques-Alain (2007), La angustia lacaniana, Buenos Aires, Paidós.

Platón (2007a), Diálogos III. Fedón, Banquete, Fedro, Biblioteca Gredos, RBA, Barcelona, 2007.

Platón (2007b), Diálogos VI. Filebo. Timeo. Critias. Cartas, Biblioteca Gredos, RBA, Barcelona, 2007.

Rabinovich, Diana (2011), «Teorías psicoanalíticas II: Los Afectos en la enseñanza de J. Lacan», Curso inédito, 2011. Descargable en scribd.

Regnault, François (2005), «Pasiones dantescas» en Virtualia. Revista Digital de la Escuela de la Orientación Lacaniana, Año IV, Número 13, Junio - Julio, 2005, en http://virtualia. eol.org.ar/013/default.asp?opinion/regnault.html. 